\title{
Crude extract yield, total phenolics, and total flavonoids from the ink of sea hare (Dolabella auricularia)
}

\author{
Janeth C. Tayone ${ }^{1, *}$, Romeo M. Del Rosario ${ }^{2}$ \\ ${ }^{1}$ Institute of Agriculture and Life Sciences, Davao Oriental State College of Science and Technology, City of Mati, 8200, Davao \\ Oriental, Philippines \\ ${ }^{2}$ Department of Chemistry, College of Science and Mathematics, University of Science and Technology of Southern Philippines, \\ Lapasan, Cagayan de Oro, 9000, Philippines
}

\section{ARTICLE INFO}

\section{Article history:}

Received 23 June 2017

Received in revised form

27 August 2017

Accepted 13 September 2017

\section{Keywords:}

Dolabella auricularia

Flavonoids

Phenolics

Pujada Bay

Sea hare

\begin{abstract}
A B S T R A C T
The crude extract yield, total phenolics and total flavonoids of the ethanol and water extracts of sea hare (Dolabella auricularia) were evaluated. The crude extract yield was determined gravimetrically while Folin-Ciocalteau and Aluminum chloride methods were used for the determination of the total phenolics and total flavonoids, respectively. The results showed that the crude extract yield for the ethanol fraction was higher $\left(7.657 \times 10^{3} \mathrm{mg} / 100\right.$ $\mathrm{mL}$ of fresh ink sample) compared to water $\left(2.937 \times 10^{3} \mathrm{mg} / 100 \mathrm{~mL}\right.$ of fresh ink sample). The same pattern was also exhibited for both total phenolics and total flavonoids where a significant difference was observed at $\mathrm{p}<0.05$. The total phenolics of the ethanol extract were higher at $2.77 \mathrm{mg}$ gallic acid / $\mathrm{mL}$ compared to that of the water extract at only $0.75 \mathrm{mg}$ gallic acid/ $\mathrm{mL}$. While the total flavonoids of the ethanol extract was $32.75 \mathrm{mg}$ quercetin $/ \mathrm{mL}$ against that of the water extract which was only $9.42 \mathrm{mg}$ quercetin/ $\mathrm{mL}$. The results indicate that ethanol is a better solvent than water for the extraction of the phenolics, flavonoids and other components. Furthermore, the presence of phenolics and flavonoids in considerable quantity suggests that ink of sea hare is a potential source of bioactive compounds that have antioxidant activity which can be developed for nutritional or pharmacological use.
\end{abstract}

(C) 2017 The Authors. Published by IASE. This is an open access article under the CC BY-NC-ND license (http://creativecommons.org/licenses/by-nc-nd/4.0/).

\section{Introduction}

Natural products from marine environment are very promising because of the incredible diversity of chemical compounds created by marine organisms. These organisms evolved with a wide variety of chemicals use for defense, communication and reproduction. One of these marine organisms is the sea hare (Dolabella auricularia). It is a slow-moving, soft-bodied mollusk with no external shell to shield them which makes them a susceptible prey. Once disturb, it releases copious ink as its chemical defense against their predators. The color of the ink ranges from dark pink to purple violet (Fig. 1). A study showed that the ink contains secondary metabolites which they obtain from their algal diet (Pennings et al., 1999; Kicklighter and Derby, 2006). Research technologies and medical advances in

\footnotetext{
* Corresponding Author.

Email Address: njtayone2005@yahoo.com (J. C. Tayone) https://doi.org/10.21833/ijaas.2017.011.003

2313-626X/@ 2017 The Authors. Published by IASE.

This is an open access article under the CC BY-NC-ND license

(http://creativecommons.org/licenses/by-nc-nd/4.0/)
}

structure elucidation and biological assay showed that these chemicals can be developed as human pharmaceuticals and used for other biomedical and industrial application (Simmons et al., 2005).

The studies about the purple ink of sea hare particularly the $D$. auricularia have shown the potential of the biologically active compounds for medicinal purposes. Some of those potential compounds found in sea hare $D$. auricularia include phenolics and flavonoids which have been reported to have multiple biological effects including antioxidant activity, anti-allergic, anti-inflammatory, anti-microbial, cytotoxin, and anti-cancer activity (Khatiwora et al., 2010; Abirami et al., 2011). Dolabellanin and dolastatin are some of the compounds isolated from $D$. auricularia which have extreme potential for chemical use as anticancer agent. In fact, dolastatin 10 is now already in its phase II clinical trials (Proksch et al., 2002).

The province of Davao Oriental has been blessed with rich diversity of natural resources in marine ecosystem. Pujada Bay is one of the known areas for its marine biodiversity which includes sea hare, Dolabella auricularia. Sea hare is commonly called as 
"dunsol". It is important among local fisher folks because the egg strings or "lukot" laid by sea hare are one of their sources of food and livelihood. The secondary metabolites produce by sea hare are dependent on their algal diet, environment and geographical location (Pennings et al., 1999; Kicklighter and Derby, 2006).

Furthermore, extraction of these is greatly affected by the type of solvent used (Dhanani et al., 2017). Although several studies on sea hare have already been conducted by other countries, however, there is no baseline information yet for sea hare from Pujada Bay which could be a good source of another biochemical and hopefully novel compounds.

This study is perhaps the first attempt to establish and quantify the secondary metabolites present in terms of the total phenolics and total flavonoids from the ink of sea hare (D.auricularia) in the region using ethanol and water as extracting solvents. The result of this study will increase the nutritional and medicinal potential values of sea hare and provide baseline information for another source of future novel antioxidants that can be used in food and pharmaceutical industries.

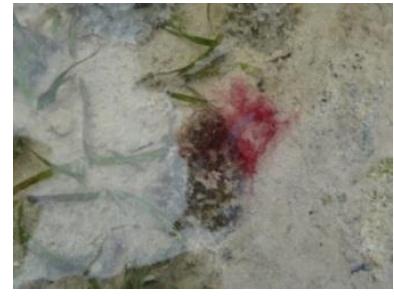

$\boldsymbol{a}$

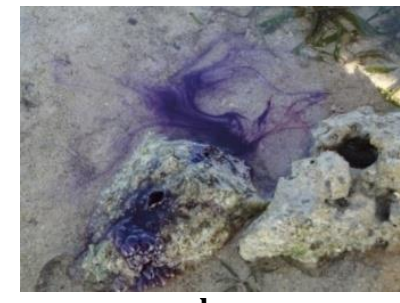

b
Fig. 1: Sea hare releasing its (a) purple ink and (b) reddish pink in the sampling site of Pujada Bay, City of Mati, Davao Oriental

\section{Materials and methods}

\subsection{Sample collection and preparation}

Five representative organisms were randomly picked by hand along the coast of Pujada Bay, City of Mati, Davao Oriental, Philippines (Fig. 2). Pujada Bay is located in Southern part of Mindanao between the coordinates of 6 648'04" and 6 654'25" N latitude and between 126 $6^{\circ} 08^{\prime \prime}$ and 126 19'33" E longitude. Samples were placed in a laboratory pan. Ink was extracted by exerting a little pressure into the organism for it to release the purple ink. All ink samples were combined in order to have one composite sample. It was then transferred into a reagent bottle and was placed in a cooler with temperature maintained at $4^{\circ} \mathrm{C}$ to preserve the integrity of the samples during its transportation to the laboratory.

About $100 \mathrm{~mL}$ of the composite sample of sea hare's ink was treated with $95 \%$ ethanol while another $100 \mathrm{~mL}$ was added with distilled water for 24 to 48 hours. The mixture was centrifuged and filtered through a Buchner funnel with gentle suction. The flask and ink extract was washed with fresh portions of alcohol and transferring the washings to the funnel to combine with the first filtrate taking note of the total volume of ethanol used. After the filtration process, the residue was discarded and the filtrate was concentrated under vacuo at temperature below $50^{\circ} \mathrm{C}$ and $100^{\circ} \mathrm{C}$ for ethanol and water respectively using rotary evaporator. The crude extract was stored in a tightly closed vial at 0 to $5^{\circ} \mathrm{C}$ until its analysis.

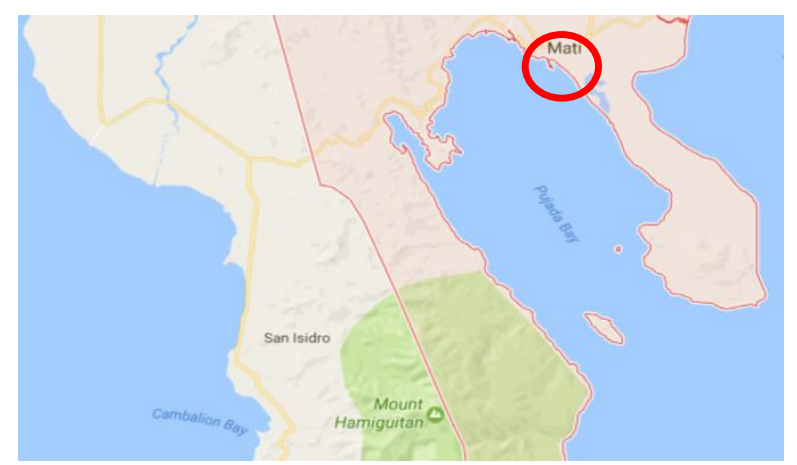

Fig. 2: The map of the sampling site located at Pujada Bay, City of Mati, Davao Oriental, Philippines

\subsection{Determination of the crude extracts concentration and yield}

Approximately $20 \mathrm{~mL}$ of extract was transferred using a pipet into a previously weighed empty dish. It was then placed in the oven at less than $50^{\circ} \mathrm{C}$ and $100^{\circ} \mathrm{C}$ for the ethanol and water fractions respectively for one hour, cooled and weighed. The process was repeated until the constant weight was obtained. On the other hand, the crude extract yield was determined by multiplying the crude extract concentration by the total volume of the crude extract solution after concentration times 100 divided by the volume of the fresh ink sample.

\subsection{Total phenolics assay: Folin - Ciocalteau method}

The Folin - Ciocalteau assay is based on the formation of a blue color (molybdenum blue) developed due to the complex redox reaction of phenols with phosphomolibdic acid present in folin ciocalteau reagent (Khatiwora et al., 2010). One mL of the extract was added to a flask with $9 \mathrm{~mL}$ distilled water. One $\mathrm{mL}$ of Folin - Ciocalteu's phenol reagent was added. The mixture was thoroughly mixed. Ten $10 \mathrm{~mL}$ of $7 \%$ sodium carbonate was added and the mixture was finally diluted to $25 \mathrm{~mL}$ with distilled water and allowed to stand at room temperature for 90 minutes. A blue color (molybdenum blue) was developed and the absorbance was measured using a spectrophotometer at $750 \mathrm{~nm}$.

Standard calibration curve was prepared using 25 to $150 \mu \mathrm{g} / \mathrm{mL}$ in $80 \%$ methanol of Gallic acid. The total phenolics were expressed as mg Gallic acid equivalents (GA) / $\mathrm{mL}$ fresh ink samples and reported as mean value $\pm \mathrm{SD}$. 


\subsection{Total flavonoids assay: Aluminum chloride colorimetric method}

The aluminum chloride method is based on the formation of stable acid complexes with the C-4 keto group and either $\mathrm{C}-3$ or C-5 hydroxyl group of flavones and flavonols with aluminum chloride (Kalita et al., 2013). About $1 \mathrm{~mL}$ aliquot of the extract solution was added to a $10 \mathrm{~mL}$ volumetric flask with $4 \mathrm{~mL}$ distilled water. Sequentially, $0.3 \mathrm{~mL}$ of $5 \%$ $\mathrm{NaNO}_{2}$ was added and allowed to stand for $5 \mathrm{~min}$. After then, $0.3 \mathrm{~mL} \mathrm{AlCl}_{3}$ (10\%) was added. After the $6^{\text {th }} \mathrm{min}$, a $2 \mathrm{~mL}$ of $1 \mathrm{M} \mathrm{NaOH}$ was added and diluted with distilled water up to the mark $(10 \mathrm{~mL})$. The solution was vigorously shaken and the absorbance was recorded at $510 \mathrm{~nm}$ wavelength. The same wavelength was used for the generation of standard calibration curve using known concentrations of quercetin (50,100,150, 200 and $300 \mathrm{mg} / \mathrm{L})$. The concentrations of total flavonoids in the sample were then calculated from the calibration plot and was expressed as mg quercetin per $\mathrm{mL}$ of fresh ink sample and reported as mean \pm SD (Ardekani et al., 2011).

\subsection{Statistical analysis}

All experimental measurements were carried out in triplicate and were expressed as the mean \pm standard deviation. A t-Test at $\mathrm{p}<0.05$ was used to determine if there was a significant difference in the crude extract yield, total phenolics and total flavonoids when using ethanol and when using water as extracting solvents.

\section{Results and discussions}

\subsection{Crude extract yield from the ink of sea hare}

Table 1 shows the yield of the crude extract from the ink of sea hare in ethanol and water fractions. The crude extract yield for ethanol fraction was significantly higher than the water fraction at $\mathrm{p}<$ 0.05 .

Table 1: The crude extract yield from the ink of sea hare

\begin{tabular}{ccc}
\hline \multirow{2}{*}{ Extract } & $\begin{array}{c}\text { Crude Extract } \\
\text { Concentration }(\mathrm{mg} / \mathrm{mL})\end{array}$ & $\begin{array}{c}\text { Yield (mg crude extract/ } \\
100 \mathrm{~mL} \text { of fresh ink) }\end{array}$ \\
\hline Ethanol & 52.07 & $7.657 \times 10^{3} \pm 45.40$ \\
Water & 19.97 & $2.937 \times 10^{3} \pm 71.56$ \\
\hline \multicolumn{2}{c}{ Each value is the average of three measurements \pm standard deviation }
\end{tabular}

The difference of the crude extract concentration might be due to the different extent of removing the solvent using rotary evaporator. Ethanol fractions are expected to give higher concentration considering that it has lower boiling point than water. Several criteria have already been used for the evaluation of the effectiveness of a particular extraction method as well as the suitability of the solvent used. The extraction yield is one of the commonly encountered criterions. It is used as an indicator of the effects of extraction solvent or condition (Sreejamole and Radhakrishnan, 2010).
The yield of extraction is also dependent on the temperature of extraction as well as the chemical nature of the sample. The solubility of the compound in the sample material is dependent on the extracting power of the solvents used. A good extracting solvent must give extracts with high yield and minimal changes to the functional properties of the extract (Dhanani et al., 2017).

In this study, ethanol is more effective in the extraction as evident by its higher value compared to water. The better yield of ethanol extract may be due to the presence of polar and nonpolar components of the compounds present in the ink of sea hare. This makes it more soluble in a polar organic solvent like ethanol than a polar inorganic solvent like water. This result is the same with the study of (Stanojevic et al., 2009; Sultana et al., 2009) where ethanol gave higher yield compared to water.

\subsection{Total phenolics extracted from the ink of sea hare}

The total phenolics (Table 2) was expressed in terms of gallic acid equivalent (GA) and calculated with a linear equation based on a standard curve $(\mathrm{y}=$ $\left.0.0028 \mathrm{x}-0.0305, \quad \mathrm{r}^{2}=0.9826\right)$. The higher concentration of the total phenolics was measured in ethanol extract ( $2.77 \mathrm{mg} \mathrm{GA} / \mathrm{mL}$ ) compared to the water extract $(0.75 \mathrm{mg} \mathrm{GA} / \mathrm{mL})$. A significant difference was observed between the total phenolics of ethanol and water extract at $(\mathrm{p}<0.05)$.

Table 2: Total phenolics from the fresh ink sample expressed in terms of mg gallic acid equivalents/ $\mathrm{ml}$ fresh

\begin{tabular}{cc}
\multicolumn{2}{c}{ ink (mg of GA/mL fresh ink) } \\
\hline Extract & $\mathrm{mg} \mathrm{GA} / \mathrm{mL}$ fresh ink \\
\hline Ethanol & $2.77 \pm 0.14$ \\
Water & $0.75 \pm 0.14$
\end{tabular}

Each vale is the average of three analyses \pm standard deviation

The results revealed that ethanol was more efficient in extracting the total phenolics from the ink of sea hare. It is shown in Tables 1 and 2 that extracting solvent with higher yield also gave higher phenolics content. The efficiency of the total phenolics extraction was greatly dependent on the type of sample and the kind of extracting solvent used (Jang et al., 2007; Jakopic and Veberic, 2009). The total phenolics in the ink of sea hare are almost comparable with that of sea cucumber, Cucumaria frondosa as studied by Mamelona et al. (2007). The total phenolics of sea cucumber ranges from 0.225 to $2.36 \mathrm{mg}$ of gallic acid per gram which was concluded to be a useful source of antioxidants for human consumption. Phenolics are generally known to have an antioxidant activity. It has redox properties that absorb and neutralize free radicals, scavenging singlet or triplet oxygen as well as decomposing peroxides.

The study of Cherif et al. (2015) showed that Aplysia depilans ink, a depilatory sea hare, contains a large number of compounds with antioxidant properties. Aqueous ink extract was effective in scavenging DPPH radicals and exhibited reducing 
power activity with an $\mathrm{IC}_{50}$ at $0.94 \mathrm{mg} / \mathrm{mL}$ and 39.4 $\mu \mathrm{g} / \mathrm{mL}$ respectively. Although these are lower than the $\mathrm{IC}_{50}$ of the standards used but it is still said to be the strongest antioxidant activity of sea hare. It has to be noted also that the chemical composition of the ink is not the same in all ink releasing mollusk. Hence, it is possible that our sea hare can also exhibit comparable antioxidant activity with Aplysia depilans or even better.

\subsection{Total flavonoids from the ink of sea hare}

The total flavonoids was expressed in terms of quercetin equivalent per $\mathrm{mL}$ of extract (Table 3) with the linear equation based on the standard curve: $\mathrm{y}=0.0002 \mathrm{x}+0.0017, \mathrm{r}^{2}=0.9941$ ). The concentration of flavonoids in fresh ink sample from sea hare ranged from 9.42 to $32.73 \mathrm{mg} / \mathrm{mL}$. The ethanol fraction had higher total flavonoids as compared to the water fraction with a significant difference at $\mathrm{p}<0.05$.

Table 3: Total flavonoids form the fresh ink sample of sea hare expressed in terms of mg quercetin per $\mathrm{ml}$ of fresh ink sample

\begin{tabular}{cc}
\hline Extract & $\mathrm{mg}$ Quercetin / mL of fresh ink \\
\hline Ethanol & $32.73 \pm 0.55$ \\
Water & $9.42 \pm 0.11$ \\
\cline { 2 - 2 } Each value is the average of three analyses \pm standard deviation
\end{tabular}

The total flavonoids of sea cucumber ranges from 0.029 to $0.598 \mathrm{mg}$ of rutin equivalents per 100 gram. The flavonoids in sea cucumber is significantly correlated with the antioxidant activity and suggested to be mainly responsible for the observed activities (Mamelona et al., 2007). Usually, the total phenolics and total flavonoids in plants using different extracting solvents will range from 5 to 10 mg quercetin / g of dry plants. The total flavonoids from the ink of sea hare especially for ethanol extract was much higher compared to that of the plants. Hence, the results strongly suggested that ink of sea hare can also be a good source of bioactive compounds with good antioxidant activity. The studies of sea hare with pharmacological effects could be attributed to the presence of these valuable components.

It is believed that secondary metabolites of sea hare are obtained from their algal diet. With these, the flavonoids, phenolics and other bioactive compounds in the ink of sea hare may also be obtained from the algae. The study of Varshney and Singh (2013) showed that algae are one of the richest sources of bioactive compounds with a wide range of therapeutic applications. Compounds with potent potential in treating cancer are isolated from algae which include dolastatin 10 that were also isolated sea hare.

\section{Conclusion}

The results of this study show that the extracting solvent greatly affects the crude extract yield and the extraction of phenolics and flavonoids from the ink of sea hare from Pujada Bay, Davao Oriental. The presence of phenolics and flavonoids in considerable quantity suggest that ink of sea hare potentially has antioxidant activity as based on the characteristics of these compounds. Further, this study shows that the ink of sea hare can be a source of bioactive compounds that can be developed for nutritional or pharmacological use.

\section{Acknowledgement}

The authors would like to acknowledge the Research, Development and Extension Division of Davao Oriental State College of Science and Technology for providing the funds for this study.

\section{References}

Abirami P, Arumugam M, Ajithkumar TT, and Balasubramanian T (2011). Isolation and characterization of $37 \mathrm{kDa}$ heparinase from the purple fluid of Dolabella auricularia. Indian Journal of Geo-Marine Siences, 40(1): 112-116.

Ardekani MRS, Hajimahmoodi M, Oveisi MR, Sadeghi N, Jannat B, Ranjbar AM, and Moridi T (2011). Comparative antioxidant activity and total flavonoid content of Persian pomegranate (Punica granatum L.) cultivars. Iranian Journal of Pharmaceutical Research: IJPR, 10(3): 519-524.

Cherif E, Lahbib K, Charaf M, and Yahaia MND (2015). Antioxidant activity of Aplysia depilans ink collected from Bizerte Channel (NE Tunisia). Algerian Journal of Natural Products, 3(1): 138145.

Dhanani T, Shah S, Gajbhiye NA, and Kumar S (2017). Effect of extraction methods on yield, phytochemical constituents and antioxidant activity of Withania somnifera. Arabian Journal of Chemistry, 10(1): S1193-S1199.

Jakopic J and Veberic R (2009). Extraction of phenolic compounds from green walnut fruits in different solvents. Acta Agriculturae Slovenica, 93(1): 11-15.

Jang HD, Chang KS, Huang YS, Hsu CL, Lee SH, and Su MS (2007). Principal phenolic phytochemicals and antioxidant activities of three Chinese medicinal plants. Food Chemistry, 103(3): 749-756.

Kalita P, Tapan BK, Pal TK, and Kalita R (2013). Estimation of total flavonoids content (TFC) and anti-oxidant activities of methanolic whole plant extract of Biophytum sensitivum Linn. Journal of Drug Delivery and Therapeutics, 3(4): 33-37.

Khatiwora E, Adsul VB, Kulkarni MM, Deshpande NR, and Kashalkar RV (2010). Spectroscopic determination of total phenol and flavonoid contents of Ipomoea carnea. International Journal of ChemTech Research, 2(3): 16981701.

Kicklighter CE and Derby CD (2006). Multiple components in ink of the sea hare Aplysia californica are aversive to the sea anemone Anthopleura sola. Journal of Experimental Marine Biology and Ecology, 334(2): 256-268.

Mamelona J, Pelletier É, Girard-Lalancette K, Legault J, Karboune S, and Kermasha S (2007). Quantification of phenolic contents and antioxidant capacity of Atlantic sea cucumber, Cucumaria frondosa. Food Chemistry, 104(3): 1040-1047.

Pennings SC, Paul VJ, Dunbar DC, Hamann MT, Lumbang WA, Novack B, and Jacobs RS (1999). Unpalatable compounds in the marine gastropod Dolabella auricularia: Distribution and effect of diet. Journal of Chemical Ecology, 25(4): 735-755.

Proksch P, Edrada R, and Ebel R (2002). Drugs from the seascurrent status and microbiological implications. Applied Microbiology and Biotechnology, 59(2): 125-134. 
Simmons TL, Andrianasolo E, McPhail K, Flatt P, and Gerwick WH (2005). Marine natural products as anticancer drugs. Molecular Cancer Therapeutics, 4(2): 333-342.

Sreejamole KL and Radhakrishnan CK (2010). Preliminary qualitative chemical evaluation of the extracts from mussel Perna viridis. International Journal of Pharmaceutical Sciences Review and Research, 5(2): 38-42.

Stanojević L, Stanković M, Nikolić V, Nikolić L, Ristić D, Čanadanovic-Brunet J, and Tumbas V (2009). Antioxidant activity and total phenolic and flavonoid contents of Hieracium pilosella L. extracts. Sensors, 9(7): 5702-5714.

Sultana B, Anwar F, and Ashraf M (2009). Effect of extraction solvent/technique on the antioxidant activity of selected medicinal plant extracts. Molecules, 14(6): 2167-2180.

Varshney A and Singh V (2013). Effects of algal compounds on cancer cell line. Journal of Experimental Biology and Agricultural Sciences, 1(5): 337-352. 